CBIE-LACLO 2015

Anais dos Workshops do IV Congresso Brasileiro de Informática na Educação (CBIE 2015)

\title{
A "leitura" do software de programação Scratch realizada pelo professor: uma pesquisa em ação
}

\author{
Valkiria Venancio', Oscar João Abdounur² \\ ${ }^{1}$ Faculdade de Educação - Universidade de São Paulo (USP) \\ Av. da Universidade, 308 - Cidade Universitária - Butantã -SP \\ ${ }^{2}$ Instituto de Matemática e Estatística - Universidade de São Paulo (USP) \\ Rua do Matão, 1010 - Cidade Universitária - Butantã -SP \\ venancio@1si.usp.br, abdounur@ime.usp.br
}

\begin{abstract}
This article intends to share research development at the doctoral level on using Scratch programming software in the classroom under the anti-essentialist assumption technology, which comes from the fact of treating technology as text, users as its readers and its writers as designers. To do this briefly describes the diagnostic steps already taken and observations in class in progress. Here we highlight the role of the methodology and process-tracing analysis technique as inspiration to colleagues who develop qualitative research.

Resumo. Este artigo intenta compartilhar um projeto de pesquisa em desenvolvimento, em nivel de doutorado, sobre o uso do software de programação Scratch em sala de aula sob o pressuposto antiessencialista de tecnologia, que vem do fato de tratar a tecnologia como texto, os usuários como seus leitores e seus escritores como designers. Para tal descreve-se brevemente as etapas de diagnóstico já realizadas e as observações em sala de aula em andamento. Destaca-se aqui o papel da metodologia e a técnica de análise process-tracing como inspiração aos colegas que desenvolvem pesquisa qualitativa.
\end{abstract}

\section{Breve Introdução}

Enfrentamos tempos acelerados de desenvolvimento das tecnologias digitais de informação e de comunicação - TDIC, tempos de valorização da criatividade e empreendedorismo. Saber lidar com novos conceitos de tempo e espaço, novas formas de trabalho, dentre incertezas, mudanças, problemas e soluções inesperadas apresenta-se como a nova maneira de aprender (VEEN; VRAKKING, 2009).

Veen e Vrankking (2009) declaram que para este ser - Homo zappiens, que nasce e vive nesta sociedade com ricos recursos informativos, de muitas verdades, veloz, a escola é parte de sua vida, mas não a principal parte. Mark Prensky (2001) chamou esta geração de nativos digitais, pois imersos na tecnologia não imaginam o mundo sem ela.

O Homo zappiens, da geração instantânea, desenvolve habilidades operacionais diante das TDIC que não são as que costumeiramente conhecemos, tais como, saber buscar e processar as informações necessárias, trabalhar em redes colaborativas e simultaneamente em várias atividades, ele possui outras estratégias de aprendizagem e aqui a educação se inverte, eles nos ensinam (VEEN; VRAKKING, 2009; GÜTL, 2009; ASSMANN, 2000; VENANCIO e LOPES, 2012).

Nesta situação como funcionaria e qual seria o papel da escola e do seu professor para esta geração? 


\section{CBIE-LACLO 2015}

Anais dos Workshops do IV Congresso Brasileiro de Informática na Educação (CBIE 2015)

O trabalho com projetos colaborativos de aprendizagem utilizando as tecnologias como ferramenta vem se constituindo em uma estratégia que possivelmente ajude a suprir, momentaneamente, a necessidade da escola na sua luta por "encaixar" as TDIC em seu atual modelo. E, ao desenvolver projetos com o uso de software de programação o aluno torna-se protagonista e autor, utiliza o computador para construir seu conhecimento (PAPERT, 1986). Papert (1994) reafirma que o software de programação é algo para ser aprendido e não apenas para ser usado, uma vez que se aprende para sabe-lo e, quando já se sabe, coloca-se nos bancos de memória.

"Ser fluente em uma língua, é saber articular uma ideia complexa, em outras palavras, você precisa saber 'fazer coisas' com essa língua. Analogamente, ser digitalmente fluente não é apenas saber como usar ferramentas tecnológicas, mas também saber como construir coisas significativas com elas" (PAPERT e RESNICK, 1995).

A pesquisa em andamento aqui descrita busca observar como o professor desta escola lê e interpreta o software de programação Scratch para criar suas "técnicas metodológicas para ensinar", na busca de soluções à uma situação problema dentro da estratégia inicial de projetos colaborativos de aprendizagem.

A chamada leitura realizada pelo professor vem do fato de se tratar a tecnologia como texto, os designers como seus escritores e os usuários os seus leitores. Abordagem esta que Grint e Woolgar (1997) denominaram antiessencialista das tecnologias. "O papel crucial da interpretação $e$ persuasão sugere que precisamos assistir de perto ao processo de interpretação ao invés de assumir que estamos persuadidos pela eficácia da tecnologia" (GRINT; WOOLGAR, 1997).

\subsection{Abordagem antiessencialista da tecnologia}

$\mathrm{Na}$ visão de Lins (2002) é preciso entender o que é uma visão essencialista de meios tecnológicos e que diferença uma visão antiessencialista pode fazer. E assim, Lins (2002A) descreveu em sua tese as abordagens das visões essencialistas de acordo com as dimensões sociais e culturais da tecnologia, que se apresenta aqui resumidamente:

a) Determinismo tecnológico: não levou em conta as dimensões sociais e culturais, afirmando que os mais "apropriados" sobrevivem às inovações e apenas aqueles que se adaptarem a essas inovações prosperarão. Visão essencialista radical por retratar a tecnologia como um desenvolvimento autônomo que determina organizações sociais e econômicas e relações.

b) Teoria dos sistemas sócio-técnicos: inclui elementos para a tecnologia: pessoas, organizações, gêneros, grupos de interesse e outros. Carrega a suposição implícita de que a natureza e capacidade tecnológicas permanecem fora do âmbito da análise sociológica, isto é, são tratadas como dado objetivo e sem problemas - 'tecnicismo'.

c) Moldar social: a capacidade da tecnologia é equivalente às circunstâncias políticas da sua produção. Afirma que a análise social deve levar em conta a tecnologia em si. Há uma limitação colocada sobre os aspectos sociais da tecnologia como apenas o processo de concepção e implementação subestimando a importância das interpretações dos atores e suas utilizações.

d) Aproximação sócio-técnica: considera a importância do alinhamento entre tecnologia e sociedade. Pesquisadores afirmam que os efeitos da tecnologia são o resultado de forças sociais e as culturais e não da tecnologia em si (Harbermas, 1971 e Hill, 1988; apud LINS, 2002). A tecnologia deve ser considerada como um um artefato que só pode ser trazido à vida através de um "texto cultural" (GRINT e WOOLGAR, 1997). O que parece ser 


\title{
CBIE-LACLO 2015
}

Anais dos Workshops do IV Congresso Brasileiro de Informática na Educação (CBIE 2015)

problemático desta abordagem é que por considerar a tecnologia como um texto cultural pode-se assumir que esta pode se tornar transparente tornando-a independente de qualquer usuário particular ou intérprete.

E por fim, teremos a abordagem antiessencialista da tecnologia onde "a capacidade $e$ capabilidade da tecnologia não são nunca transparentemente óbvias e necessariamente requerem alguma forma de interpretação; tecnologia não fala por si mesma mas tem que ser falada por..." (GRINT, WOOLGAR 1997, p. 32).

\subsection{Projetos colaborativos de aprendizagem como incentivo à criatividade e ação}

Fagundes e outros (2006) descrevem projetos de aprendizagem (PA) como uma estrutura composta de objetivos e estratégias pedagógicas com o uso de recursos tecnológicos; e que durante suas etapas de desenvolvimento há criação de conteúdos que permitem a existência de redes de conhecimento.

Os PA se iniciam com levantamento de situações problemas vivenciadas pelos alunos que os estimulam a questionamentos e busca de soluções; os alunos se agrupam em torno das questões a serem investigadas e levantam o que já sabem e o que precisam pesquisar para construir/encontrar a solução para o problema (FERRARI et al., 2014).

As TDIC contribuem imensamente para que projetos desenvolvidos, dentro desta estrutura de PA, possam ser compartilhados, editados e refletidos coletivamente, possibilitando assim a construção de projetos colaborativos de aprendizagem efetivos para a/as soluções de uma situação problema, que geralmente são interdisciplinares, ou seja, vão além das disciplinas curriculares envolvendo comunidade intra e extra escolar (FAZENDA, 1996). Nesta perspectiva, Araújo (2011) propõe um novo papel ao professor considerando que:

\begin{abstract}
"os profissionais da educação precisam entender e assumir uma postura acadêmico-científica que leve à reinvenção da educação. Esse modelo de escola e de universidade consolidado no século XIX tem agora, também, de dar conta das demandas e necessidades de uma sociedade democrática, inclusiva, permeada pelas diferenças e pautada no conhecimento inter, multi e transdisciplinar, como a que vivemos neste início de século XXI”. (ARAÚJO, 2011)
\end{abstract}

\section{$1.3 \mathrm{O}$ software de programação: instrumento na resolução de problemas}

Ao considerarmos a programação como um meio para apresentação e construção de soluções para situações problemas encontradas e propostas pelos alunos, a programação com o software $\operatorname{Scratch}^{1}$ possibilita o desenvolvimento de simulações, histórias, animações e jogos, além de juntamente com outras tecnologias, a robótica.

Ressalta-se que o trabalho com qualquer que seja a tecnologia é dinâmico, e este acontece se ocorrerem mudanças nas concepções metodológicas, de maneira a considerar o aluno protagonista na construção do seu conhecimento. Tais mudanças somente ocorrerão com formação adequada a professores, que considere as realidades das escolas e seus projetos políticos pedagógicos, bem como as necessidades tanto de professores quanto de alunos, estando o professor em situações que possa refletir sobre a prática (VENANCIO et al., 2012).

\footnotetext{
${ }^{1} \mathrm{https}: / /$ scratch.mit.edu
} 


\section{CBIE-LACLO 2015}

Anais dos Workshops do IV Congresso Brasileiro de Informática na Educação (CBIE 2015)

Este artigo pretende compartilhar parte da pesquisa em desenvolvimento e para tal na seção um destaca-se o papel da sociedade digitalizada e daqueles nela nascidos, assim como da importância de projetos colaborativos de aprendizagem como mais uma estratégia de ensino e do software de programação como instrumento na resolução de problemas. Na seção dois descreve-se brevemente os pressupostos, objetivos e questão da pesquisa. A seção três descreve as etapas de desenvolvimento metodológico já encaminhadas e em andamento. E finalmente, na quarta seção apresentamos algumas considerações.

\section{Um plano em construção}

Tendo como pressuposto a visão antiessencialista colocada, a pesquisa tem como objeto a relação professor e aluno no uso pelo professor orientador de informática educativa (POIE) do software de programação Scratch junto a alunos do ensino fundamental - entre 09 e 14 anos de idade, em escolas da rede municipal de ensino de São Paulo.

Questiona-se de que modo e em que extensão podemos compreender as contribuições das novas TDIC nos processos de ensino e de aprendizagem? Qual uso professores e alunos fazem da máquina a partir das leituras e interpretações realizadas do software de programação Scratch? É possível que a leitura e interpretação realizada pelo professor sobre o software de programação Scratch o leve a criar novas técnicas metodológicas que são aplicadas em sala de aula para explicar, compreender e aprender? Qual é efetivamente a responsabilidade social de se trabalhar com as tecnologias enquanto "geradora" de conhecimento?

Há muito Valente (1993) apontava que o trabalho com software de programação na educação parte do princípio de ser mais uma ferramenta para aprendizagem baseada em resolução de problemas. Resolver problemas por meio da linguagem computacional propicia, partindo-se do nada, uma construção lógico-matemática e formal, que ao ser executada possibilita verificação, análise, identificação e depuração dos conceitos e ideias desenvolvidas, assim como, dos erros (VALENTE, 1993).

Neste sentido, a solução do problema desenvolvida ou representada por meio do software de programação, no nosso caso o Scratch, é uma construção própria, protagonizada individual ou coletivamente, que transforma usuários-leitores em designers, ou seja, em escritores do texto. Ampliado pela possibilidade do compartilhamento e colaboração de projetos no Brasil e outros países, possível pelo site do Scratch.

\section{O plano em ação}

$\mathrm{Na}$ busca incessante de melhorias do processo de ensino e de aprendizagem procura-se contribuir para que professores e alunos da educação básica deixem de ser simples usuários passivos e utilizem as tecnologias em sala de aula ativamente, como criadores/produtores/colaboradores.

Para pesquisa, em sua primeira etapa metodológica, efetivada no segundo semestre de 2014, realizou-se um curso semipresencial de formação introdutória ao Scratch a cerca de cem professores do ensino fundamental do município de São Paulo, com aplicação simultânea na escola junto a seus alunos (Figura 1). O curso com duração de dezesseis horas presenciais e encontros virtuais de apoio a distância, tinha como princípio o levantamento de problemas, soluções e propostas efetivas para a "Cidade que a Gente Quer" - título da formação, a serem construídas no software de programação.

\footnotetext{
${ }^{2}$ http://informaticaeducativa.educapx.com/a-cidade-que-a-gente-quer.html
} 


\section{CBIE-LACLO 2015}

Anais dos Workshops do IV Congresso Brasileiro de Informática na Educação (CBIE 2015)

Durante a formação buscou-se conhecer a população alvo aplicando-se questionário diagnóstico a todos os cursistas. Os encontros posteriores pré agendados em grupo virtual reflexivo síncrono serviram de apoio à aplicação da oficina junto aos alunos e obtenção de informações sobre o andamento dos projetos nas escolas. Ao término da formação aplicou-se o questionário avaliativo final.

$\mathrm{Na}$ segunda etapa, se dará o estudo de caso com a pesquisadora atuando de forma autônoma e revelada (ARNSTEIN, 1969), utilizando-se da observação e diário de pesquisa durante o uso do Scratch e outros softwares por três professores, em laboratórios de informática de diferentes escolas para coleta de dados, tendo como pressuposto, que "pesquisar $e$ ensinar-aprender são partes do mesmo processo de conhecer, isto é, de compreender, intervir e transformar a realidade" (BRANDÃO; STRECK, 2006). Por fim, a estratégia process-tracing descrita abaixo, será aplicada para posterior análise.

\subsection{Etapas de desenvolvimento metodológico}

Primeira Etapa: Levantamento e conhecimento da população alvo

a) Questionário diagnóstico online foi aplicado aos professores cursistas da formação semipresencial "A Cidade que a Gente Quer" junho/julho de 2014, com interesse em conhecer sua formação acadêmica, tempo de atuação na educação e na função de POIE, sua jornada diária de trabalho, atitudes diante da tecnologia e sua experiência com software de programação para educação (Figura 1).
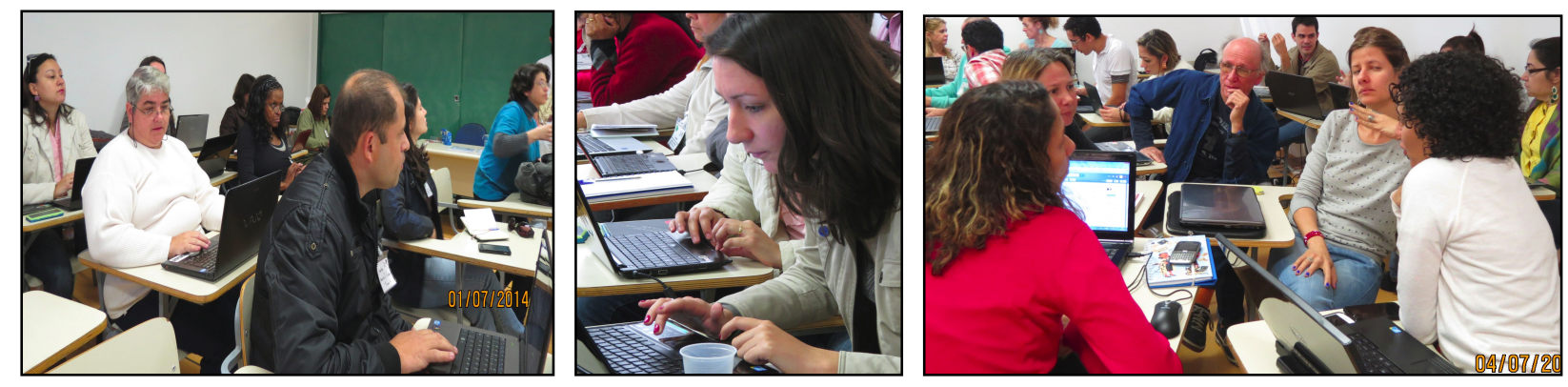

Figura 1: Encontro presencial da Formação "A Cidade que a Gente Quer"

Verificou-se que a maioria dos professores atuam na educação há mais de 10 anos (52\%) e possuem formação mínima em nível de Lato sensu (52\%); destes, os que exercem a função de POIE, o fazem há menos de 5 anos (67\%).

A grande maioria (87\%) enfrenta jornada semanal de 36 horas/aula (h/a=50 minutos), sendo $25 \mathrm{~h} / \mathrm{a}$ com alunos e $11 \mathrm{~h} / \mathrm{a}$ em horário coletivo com os pares; e não acumulam cargo $(57 \%)$, ou seja, trabalham em uma única escola.

Outro destaque do questionário está no fato de $46 \%$ dos cursistas nunca terem trabalhado com software de programação com seus alunos e $17 \%$ o fizeram muito pouco.

b) Grupo virtual reflexivo online, denominado "Traz pra Roda" realizado em cinco encontros um em julho, dois em agosto e dois em setembro/2014, por meio de rede social, tinha participação espontânea. Nos cinco encontros tivemos sete postagens introdutórias reflexivas, 3 no primeiro encontro e uma única nos encontros seguintes. Totalizou-se 250 cursistas participantes, sincronamente e alguns assíncronos, sendo 71 no primeiro encontro, 63 no segundo, 47 no terceiro, 46 no quarto e 23 no quinto encontro, o qual ocorreu problema com a Internet. Comentários/interações em todos os cinco encontros perfizeram o total de 630 postagens. 


\section{CBIE-LACLO 2015}

Anais dos Workshops do IV Congresso Brasileiro de Informática na Educação (CBIE 2015)

O "Traz pra Roda" buscou colaborativamente apoio, orientação e levantamento dos caminhos encontrados pelos professores para o desenvolvimento de projetos junto aos alunos. Já para pesquisadora proporcionou a procura inicial da "leitura" realizada pelos professores cursistas sobre o Scratch.

Os comentários/interações postados pelos professores cursistas apontaram três indicadores: contextualização - observando-se a busca de tema incentivador para o trabalho com o software. Conteúdo - quando a postagem voltava-se para questões de conteúdo e técnicas de programação. E estratégia - interações voltadas às questões metodológicas de ensino e de aprendizagem e ações colaborativas. Destacam-se alguns depoimentos de diferentes encontros:

\section{Contextualização}

"Paula o projeto vai além dos muros da escola. Esta reflexão é bastante pertinente, a cidade é de todos e a preocupação para melhoria também." (prof. E.Q.) - $2^{\circ}$ encontro.

\section{Conteúdo}

"Apresentei aos alunos do $5^{\circ}$ e do $6^{\circ}$ ano o Scratch. Eles curtiram a ideia de programação de jogos, porém o processo está no início. No momento eles estão na fase de 'experimentação' estão se familiarizando com este novo tipo de linguagem" (prof. P.A.) - $1^{\circ}$ encontro;

"Em uma das animações o personagem voltava de ponta cabeça, não estava conseguindo resolver, na outra aula o aluno achou o problema, era na rotação da imagem, não era nos operadores" (prof. C.N.) - $3^{\circ}$ encontro.

\section{Estratégia}

"Como o tema sustentabilidade está sendo trabalhado na escola coletivamente, tem ficado mais fácil debater o tema e já ligá-lo ao Scratch. Alguns alunos tem dificuldade em expressar a ideia através do Scratch, então estamos trabalhando em esquema de colaboração. Quem consegue algo bacana explica para os colegas como realizou a atividade” (prof. M.E.P.L.) - $2^{\circ}$ encontro;

"Essa busca por soluções no próprio site do Scratch é a melhor alternativa mesmo prof. I.F. ... meus alunos estão ficando craques em buscar soluções, pois perceberam que eu não consigo responder a todas as perguntas..." (prof. M.F.) - $4^{\circ}$ encontro.

Observa-se nos comentários destacados que os professores promoveram momentos de exploração do software e busca de soluções, além de disponibilizarem material de apoio, o que possibilita aos alunos novas descobertas e autonomia para desenvolverem seus projetos e atingirem os resultados esperados ao resolverem, sozinhos ou colaborativamente, problemas encontrados. $\mathrm{O}$ "Traz pra Roda" também possibilitou a troca de conhecimento entre os professores com dificuldades, que estavam iniciando o projeto.

c) Questionário avaliativo final online realizado com o intuito de conhecer entraves e facilidades encontrados no percurso do curso, listar projetos desenvolvidos com o software, reconhecer suas atitudes diante do aluno e do seu olhar sobre as atitudes do próprio aluno, verificar o que pensa sobre o impacto do Scratch nas áreas do conhecimento.

Como avaliação do curso os professores deveriam desenvolver projeto com alunos e cada um escolheu em qual nível ou com quantos o faria. A maioria o desenvolveu com alunos do ciclo II do ensino fundamental (75\%), 54\% com alunos do ciclo I ou com ambos, e outros $11 \%$ somente o fizeram com os alunos monitores - alunos que, no contra turno, auxiliam o POIE durante as aulas no laboratório de informática educativa. 


\section{CBIE-LACLO 2015}

Anais dos Workshops do IV Congresso Brasileiro de Informática na Educação (CBIE 2015)

Ao se questionar sobre o impacto do software de programação nas áreas de conhecimento 79\% dos professores acreditam que o mesmo ocorre em todas as áreas reafirmado pelo depoimento do professor abaixo (Figura 2).

"O software de programação Scratch, e muitos outros deste tipo, pode potencializar o aprendizado do aluno no Laboratório de Informática. Afinal, opera-se com uma lógica que o educando não está acostumado, ou seja, instaura-se uma outra maneira de pensar, de obter conhecimento. Além disso, o fato de lidar com uma proposta que está em consonância com a realidade dos alunos é propiciado, para aqueles que estão interessados, uma adesão fácil à proposta. Afinal, os alunos verificam rapidamente a possibilidade de serem autores de jogos e de animações, o que lhes motiva, a cada dia, a aprender e a experimentar o software de programação. Cabe ressaltar também que o universo dos softwares de programação são amplos e interdisciplinares. A produção de um jogo, por exemplo, pode envolver o conteúdo de várias disciplinas, como questões envolvendo o domínio da modalidade formal da língua e problemas ambientais da cidade de São Paulo" (Prof. A.N.A.).

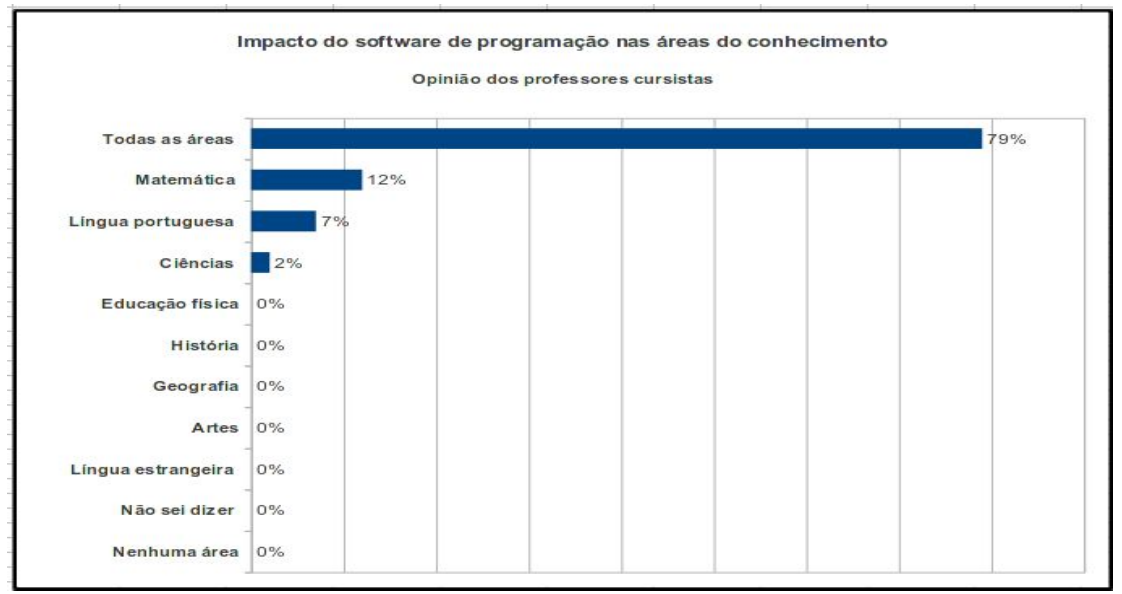

Figura 2: O impacto do trabalho com software de programação nas áreas do conhecimento

No que se refere a relação com o aluno no uso do software de programação $63 \%$ dos professores declararam que ambos aprenderam juntos, mas ensinaram os primeiros passos (53\%) e ajudaram a buscar soluções em outros sites (60\%).

Já na visão dos professores em relação ao comportamento do aluno no uso do software de programação, 53\% apontam que os alunos compartilham colaborativamente o trabalho, no entanto, cerca de metade dos professores declaram que somente alguns alunos buscam informações independentemente do professor (44\%) ou tentam descobrir novos recursos $(49 \%)$ ou diferentes estratégias (44\%). Poucos professores observaram alunos buscarem outros recursos para o desenvolvimento de seu projeto $(35 \%)$, demonstrarem autonomia $(11 \%)$ ou relacionarem seus projetos a outros conteúdos escolares (23\%), que são atitudes que se buscam desenvolver na escola.

Segunda Etapa: Coleta de dados para análise

a) Observação em sala de aula (2015), de forma não participante, se dá em três escolas, escolhidas aleatoriamente, semanalmente em um total de 30 aulas, dois deles são professores que declararam no questionário avaliativo final sua intenção de continuidade do projeto no ano seguinte $(88 \%)$ e um que não participou da formação.

Os casos que serão o foco da pesquisa deverão manifestar concordância. Pretende-se realizar anotações em diários como apoio às observações. Posteriormente, intenta-se apresentar aos participantes o que foi descrito, a fim de buscar a máxima transparência. 


\section{CBIE-LACLO 2015}

Anais dos Workshops do IV Congresso Brasileiro de Informática na Educação (CBIE 2015)

O roteiro de observação, levará em consideração os objetivos e hipótese da pesquisa. Ou seja, deve-se observar atentamente, a fim de encontrar indícios, de qual é a "leitura" realizada pelo professor do Scratch para desenvolver seu trabalho junto aos alunos.

b) Questionário pós observações (2015) será realizado com os três professores participantes como instrumento adicional, estruturado, com perguntas abertas e fechadas.

c) Estratégia process-tracing (2015/2016) buscará, por meio das observações e do questionário pós, o levantamento de indicadores e fatores que articulados apontam para a direção da aprendizagem objetivada pelos professores.

Segundo Collier (2010), process-tracing ou sondagem de processos é um mecanismo causal que examina evidências coletadas com a intenção de apurar e refinar as inferências a serem realizadas.

Rezende (2011) acrescenta em seu artigo, que process-tracing é um método que se utiliza de observações intensivas e busca compreender profundamente como as causas e processos se articulam e, complementa, que a busca das causas geradas pelos efeitos é adequada para a produção de inferências causais.

Esta estratégia de estudo de caso, que se intenta nesta pesquisa, buscará abordagem comparativa em que, segundo Beach e Pedersen (2013), "envolve a construção de uma teoria sobre um mecanismo causal entre X e Y, que pode ser generalizado para a população de um determinado fenômeno, a partir de uma situação em que estamos no escuro quanto a tal mecanismo".

Mediante o exposto pelos autores citados sobre a técnica do process-tracing, inicia-se uma reflexão sobre suas possibilidades para a pesquisa em curso, brevemente descrita neste artigo.

O propósito desta pesquisa está centrado na teoria, onde busca-se construir sistematicamente um mecanismo causal plausível ligando $\mathrm{x}$ e y com base em evidências do caso, se intenta a construção de teoria. Procura-se um mecanismo único, generalizável, por meio de manifestações observáveis, reflexões e inferências.

Algumas questões surgem sobre o que possivelmente poderia ser observado intensivamente no esforço em detectar indícios (padrões, temas, características etc), a partir de situações em sala de aula (elementos contextuais), que identifiquem o como o professor lê o software de programação Scratch, para que possa criar e desenvolver suas técnicas metodológicas de ensinar:

a) Como ele explica/orienta seu aluno a usar o software?

b) Como "soluciona" as dificuldades do aluno no uso dos recursos específicos do software?

c) Quais são suas respostas às perguntas dos alunos sobre a utilização do software?

d) Como planeja a aula para o uso do Scratch e outros softwares?

e) Em que baseia-se para inserir a utilização do software?

Se houver indícios de diferentes leituras do Scratch realizadas pelos prof.A, prof.B e prof.C, contudo os três atingem o mesmo resultado, então haverá relação causal entre a leitura de cada um dos professores e suas ações? É possível inferir que são tais leituras que induzem o professor a criar técnicas para explicar, compreender e aprender (teste de hipótese)?

Que outras inferências causais são possíveis de serem extraídas de tais observações?

Enfim, a segunda etapa metodológica desta pesquisa, pretende partir de todas as reflexões aqui preliminarmente realizadas. 
CBIE-LACLO 2015

Anais dos Workshops do IV Congresso Brasileiro de Informática na Educação (CBIE 2015)

\section{Algumas considerações}

Buscou-se aqui resumidamente compartilhar o andamento da pesquisa iniciada em 2014, cujo motivo de estudo se encontra no uso, por professores de informática educativa, do software de programação Scratch junto aos alunos de modo a promover aprendizagem autônoma, criativa, construtiva e colaborativa. Com objetivo de investigar como o professor usuário "lê" tal software e a partir desta leitura cria e desenvolve suas técnicas metodológicas de ensinar, neste caso ensinar "escritores".

O trabalho dos professores com software de programação acionado por tema para desenvolvimento de projetos já é uma prática antiga, no entanto, o fato de buscar-se argumentos que demonstrem a leitura que o professor faz do Scratch para criação de suas estratégias de ensino e as possibilidades de "ver" os alunos tornando-se designers é o que atrai e poderá contribuir para os programas de formação dos educadores no uso de TDIC em sala de aula.

$\mathrm{O}$ artigo aponta a pertinência da metodologia e estratégia - process-tracing, para o desenvolvimento desta investigação, já que se continuará a reflexão sobre a mesma na intenção de aprofundar e melhorar a técnica para o caso específico desta pesquisa. No desenrolar da construção deste artigo, após várias leituras e conversas com parceiros, acredita-se estar no caminho certo e indica-se um mergulho conceitual nesta estratégia para aqueles que desenvolvem pesquisa qualitativa.

E por fim, fica aqui o endereço onde se encontram vários projetos desenvolvidos por professores participantes da formação citada, juntamente com seus alunos para o deleite de todos http://portal.sme.prefeitura.sp.gov.br/Main/Page/PortalSMESP/A-Cidade-Que-A-Gente-Quer.

Agradecimentos: Maria do Carmo Santos Domite (in memoriam); Grupo de Estudos e Pesquisas Etnomatemáticas - GEPEm da Faculdade de Educação da USP ; Núcleo de Aprendizagem, Trabalho e Entretenimento - NATE do Laboratório de Sistemas Integráveis - LSI da Escola Politécnica da USP.

\section{Referências Bibliográficas}

ARAÚJO, U. F. A quarta revolução educacional: a mudança de tempos, espaços e relações na escola a partir do uso de tecnologias e da inclusão social. ETD - Educ. Tem. Dig., Campinas, v.12, n.esp., p.31-48, mar. 2011. Disponível em https://www.fe.unicamp.br/revistas/ged/etd/article/view/2279. Acesso em: abril 2015.

ARNSTEIN, S. A ladder of citizen participation. J Inst Plan. 1969; 35: 216-224

ASSMANN, H. A Metamorfose do Aprender na Sociedade da Informação. Ciência da Informação, IBICT, Braslia, v. 29, n. 2, p. 7-15, maio/ago. 2000. Disponível em $<$ http://www.scielo.br/pdf/ci/v29n2/a02v29n2.pdf $>$. Acesso em: maio de 2015.

BEACH, D.; PEDERSEN, R. B. Process-tracing methods: foundations and guidelines. Michigan, USA. University of Michigan press, 2013.

BRANDÃO, C.R.; STRECK, D.R. (Orgs). Pesquisa participante: a partilha do saber. Aparecida, SP: Ideias e Letras, 2006.

COLLIER, D. Process Tracing: Introduction and Exercises. To Accompany Rethinking Social Inquiry, 2nd Edition, 2010. 
CBIE-LACLO 2015

Anais dos Workshops do IV Congresso Brasileiro de Informática na Educação (CBIE 2015)

FAGUNDES, L.C.; ARAGÓN, R.; BASSO, M. V. A.; BITTENCOURT, J. V.; MENEZES, C. S.; MONTEIRO, V. C. Projetos de Aprendizagem: uma experiência mediada por ambientes telemáticos. Revista brasileira de informática na educação. v. 14, n. 1, p. 29-39, 2006.

FERRARI, M.; TAVARES, O. L.; MENEZES, C. S. AProAp - Um ambiente para projetos de aprendizagem. Anais do III Congresso Brasileiro de Informática na Educação - CBIE. Dourados, MS, 2014.

GÜTL, C.; CHANG, V. Ecosystem-based Theoretical Models for Learning in Environments of the $21^{\text {st }} \quad$ Century. Disponível em: $<$ http://www.researchgate.net/profile/Christian_Guetl/publication/26584705_Ecosystem-based_The oretical_Models_for_Learning_in_Environments_of_the_21st_Century/links/0912f50ae81f01f61f0 00000.pdf $>$. Acesso em maio de 2015.

GRINT, K.; WOOLGAR, S. The machine at work: technology, work and organization. London: Polity Press, 1997.

LINS, A. The importance of premises: from an essentialist to an anti-essentialist view of ICTin matehmatics education. Rowland, T. (Ed.) Proceedings of the British Society for Research into Learning Mathematics, 20(3), November 2000

Towards an anti-essentialist view of technology in mathematics education: the case of excel and cabri-gómètre. Unpublished $\mathrm{PhD}$ thesis, degree of Doctor of Philosophy, University of Bristol, october, 2002A.

PAPERT, S. Constructionism: A New Opportunity for Elementary Science Education. A proposal to the National Science Foundation. Massachusetts Institute of Technology, Media Laboratory, Epistemology and Learning Group, Cambridge, Massachusetts. 1986.

Artes Médicas, 1994.

A máquina das crianças: repensando a escola na era da informática. Porto Alegre:

PAPERT, S.; RESNICK, M. Technological Fluency and the Representation of Knowledge. Proposal to the National Science Foundation. MIT MediaLab , 1995.

REZENDE, F. C. Razões emergentes para a validade dos estudos de caso na ciência política comparada. Rev. Bras. Ciênc. Polít., Brasília, n.6, Dec.2011. Disponível em $<\mathrm{http}: / /$ www.scielo.br/scielo.php?script=sci_arttext\&pid=S0103-33522011000200012\&lng=en\&nr $\mathrm{m}=\mathrm{iso}>$. Acesso em maio de 2015.

VALENTE, J.A. "Por que o computador na educação?”. In VALENTE, J.A. (Org). Computadores e conhecimento: repensando a educação. Campinas, SP: UNICAMP, 1993.

VENANCIO, V.; LOPES, R. D. Competências e Avaliação Formativa em Sistema Interativo de Apoio a Aprendizagem e ao Planejamento voltado ao Ensino Fundamental. Anais do I Congresso Brasileiro de Informática na Educação - CBIE, WAvalia, Rio de Janeiro, RJ, 2012.

VENANCIO, V.; CORREAA, A. G. D.; TELlES, E. de O.; CORRÊA, C. M.; GARCIA, B. V. R.; RIBEIRO, C. C.; FICHEMAN, I. K.; LOPES, R. D. (2012) "Integração dos Laptops Educacionais ao Cotidiano Escolar no UCA São Paulo: facilidades e dificuldades”. I Congresso Brasileiro de Recursos Digitais para Educação, Universidade Plesbiteriana Mackenzie, São Paulo, maio- 2012.

VEEN, W.; VRAKKING, B. Homo zappiens: educando na era digital. Porto Alegre, RS: Artmed, 2009. 